\title{
Study on the Construction Mode of Ecological and Sustainable Rain Flood in New Urban Area of China
}

\author{
Caixia Kang ${ }^{1, *}$, Qing Lu ${ }^{1}$, Zhiheng Zhang ${ }^{1}$,Qian Zhao ${ }^{1}$, and Huihui Nan ${ }^{1}$ \\ ${ }^{1}$ Urban Space Planning and Architectural Design co., LTD., Research center Department, Beijing, China.
}

\begin{abstract}
In the background of the urbanization process has exceeded 58\% of China and expansion of the construction land expansion, as a future appropriate residential development and ahead of the key area of urban rain flood management, this research expounds the new cities and new district how to follow the principle of ecological priority in different application field, and how to use land for urban green space and ecological protection for elastic development and rain flood management. The study of the new cities' ecorain flood management model is of great significance for the governance and sustainable development of urban diseases in China.By combining natural ways with artificial measures, planning is carried out in advance.On the premise of ensuring the safety of urban drainage and waterlogging prevention, the accumulation, infiltration and purification of rainwater in urban areas can be realized to the maximum extent, and the utilization of rainwater resources and ecological environment protection can be promoted in new cities. To make plan ahead,to avoid the problems of rain and flood in existing urban areas, and improve the livable quality of new cities greatly.New ways of thinking and construction guidance are proposed for ecological livable construction and flexible rain flood management of new urban areas in China.
\end{abstract}

\section{Introduction}

With the acceleration of urbanization, the construction land expands with high intensity and human activities interfere with the original natural ecosystem. China's current urbanization rate has exceeded $58 \%$, which is in the period of concentrated outbreak of urban diseases. The increase of the proportion of mat surface under water proof significantly changed the original natural hydrological ecological process. These processes lead to frequent occurrence of rainstorm waterlogging and deterioration of river ecological function non-point source pollution.The traditional urban planning is "based on drainage", and the pipe network project (grey infrastructure) "hard drainage" ,lacks natural and ecological rain and flood control facilities.Unreasonable pipe network planning and design and unsound drainage facilities result in deterioration of water ecological environment in urban areas. The construction of ecological and livable new area is the latest idea and model of China new city construction. The new cities, as a key area for future development of suitable residential areas and urban rain flood management, is usually planned with higher green land rate and more natural ecological protection land, which is highly feasible in the construction of ecological rain flood. We can integrate the elastic construction concept into the pre-planning, avoid the problems of rain and flood in the old city, and help build the new ecological residential area into a livable one. The study of the new city's eco-rain flood management model is of great significance for the governance and sustainable development of urban diseases in China.

\section{Advanced concept mode of international eco-storm flood management}

Some developed countries have well established and applied the urban ecological rain flood management model.Such as best management practices (BMPs) in the United States, water sensitive urban design (WSUD) in Australia, low impact urban design and development (LIUDD) in New Zealand, and active \& beautiful\& clean (ABC) in Singapore.[1] In the late 1980s, Germany ranked the management and utilization of rainwater as one of the three major issues of pollution control in the 1990s, and built a large amount of rainwater retention for intercepting, treating or permeating rainwater with natural topography and artificial facilities.At present, Germany has established mature and complete rainwater collection, treatment, control and infiltration technologies as well as the corresponding regulatory system.It has become one of the most advanced countries in the world.

Portland's Donald creek park is in a busy neighborhood of Portland.The base was a wetland before it was developed, using "modern new technology to recreate the past".The designers tried to recreate the wetland on the abandoned site and feature water and wetland habitat as the new park.The ecological model of

* Corresponding author: kcx1024@163.com 
rainwater garden is introduced into the design, which fully demonstrates the ecological intervention of landscape design as an "artificial nature".Located southeast of hannover, capital of the German state of Saxony, the ecological community of hannover has been listed as a key area of urban development since the 1960s due to its excellent geographical location. The urban landscape design follows the process of energy conservation, rainwater collection and reuse, and is unique. The ground water level is high, although the large-scale construction is carried out, the natural water level in the area is maintained, and the precipitation in the whole area is almost completely free of loss.Near Portland state university's residential area of NE Siskiyou "green street" in Portland, Oregon, is an 80 year residential street renovation project.The project is considered to be one of the best green street flood renovation projects in Portland.It exemplifies the principles of sustainable storm-water management and embodies the value of simple, cost-effective and innovative design solutions.

\section{Planning of ecological resilience development mode in the construction of new cities in China}

In recent years, the management of domestic rain flood has been paid great attention to, and some construction results have been achieved.The construction of several sponge city pilot projects is a good practice of the concept of ecological rain flood management.[2]It is an important subject that we need to practice and perfect in the construction of ecological rain flood construction mode in China and avoid urban diseases caused by blind development.Comrade Jinping Xi pays great attention to the ecological problems in the construction and development of the new city.In December 2013, the central urbanization work conference pointed out that "The city should be integrated into the nature by relying on the existing landscape context and other unique sceneries, so that residents can see mountains, water and nostalgia.We should integrate modern elements, protect and carry forward the excellent traditional culture, and continue the historical context of the city. The idea of making people's lives more comfortable is embodied in every detail."The Xiongan new area currently under construction adheres to the ecological priority and green development path.Integrated with a large number of advanced concepts and construction modes of ecological rain flood management, the company is committed to building a livable benchmark for future integration of urban green ecology, tradition and modernity.It is becoming a leader in the construction of ecological rain flood management model of new cities in China.

The construction of the new cities' elastic ecological rain flood needs to integrate hydrological cycle, water security, water environment, water resources and other dimensions, and integrate the rain flood management into all aspects of urban construction.Through the multidisciplinary cooperation among ecology, landscape, planning, water conservancy and municipal administration, the ecological construction mode with the priority of nature is constructed.[3]Constructing the whole-process ecological elastic control measures of "source - process - end".[4]From the traditional "hard drainage" model of engineering pipe network to the ecological storm water management (ESWM).[5]We should give play to the value of ecosystem services of urban natural ecosystems in water conservation, stormwater regulation, water quality protection and rainwater utilization.[6]How to establish the management mode applicable to the construction of new city rain flood is of great significance to the construction of China's urbanization. This paper takes the new city of Longtan as an example to propose the sustainable construction mode of new city's ecological rain flood.

\section{Management measures of ecological rain flood in Longtan new city of Nanjing}

\subsection{General situation of Longtan new city of Nanjing}

Longtan new city is located at the east gate of Nanjing in Jiangsu province of China.It is next to the Yangtze river.In the west is Qixia mountain, in the south is Baohua mountain.It is 35 kilometers from Nanjing and belongs to the new area on the edge of the city.[ Fig.1]It is an important node of the Yangtze river economic belt.Longtan new city is a typical riverside new city in the southern dike with dense water network and numerous water systems. With the acceleration of the construction of the new city, the existing unbuilt land is about to face the high intensity of development and construction.How to incorporate and integrate into the construction mode of ecological rain flood is an important content to be considered in the construction of livable ecological new city in Longtan.This study proposes detailed solutions.

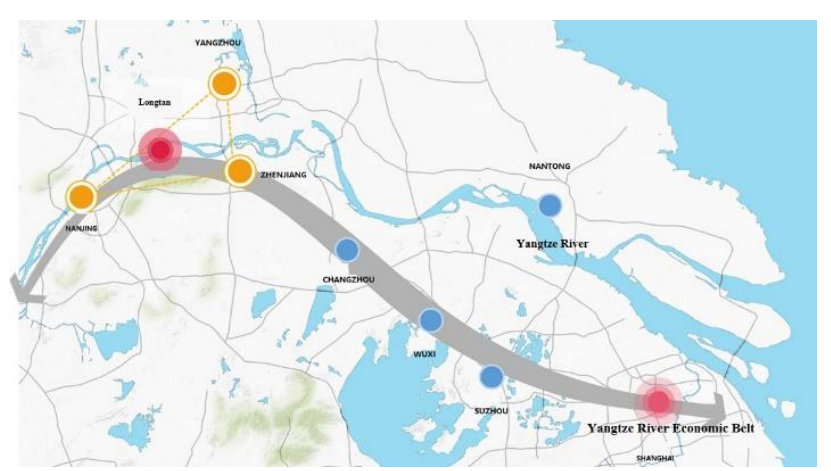

Fig. 1. Geographical location of Longtan new city

\subsection{Development and construction challenges of water ecology in Longtan new city}

\subsubsection{Background status of Longtan new city}


Longtan new city is close to the Yangtze river and Baohua mountain two ecological corridor.The planning area is densely covered with numerous water systems. [Fig.2] The average width is about 15 - 70 meters and constitutes a good ecological background for the new city.At the same time, it has a large number of artificial secondary wetlands caused by fish ponds, reservoirs and rice paddies.The integration of ecological sustainable rainflood construction is not only one of the important modes to build a livable new city of Longtan, but also an important strategy to protect the ecological quality of the Yangtze river economic belt.

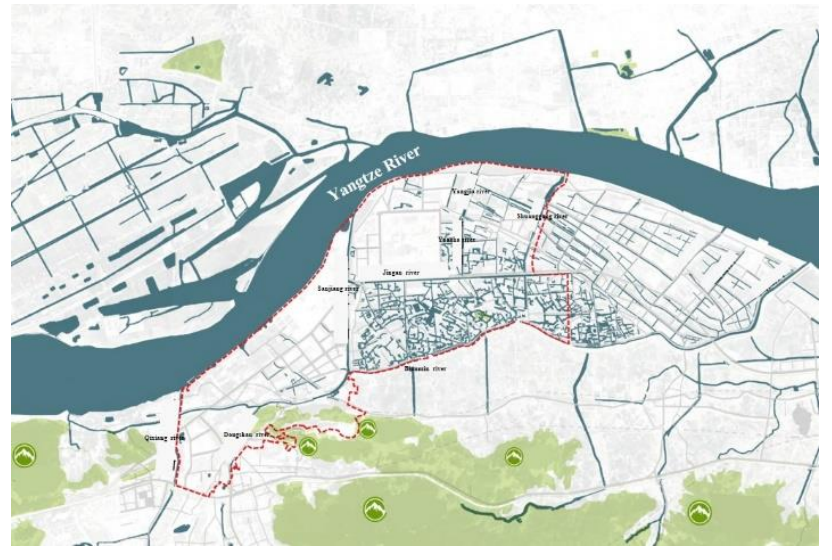

Fig. 2. Current water system of Longtan new city

In Longtan new city, there are problems such as abundant rainfall in summer, low topography in traditional polder area and easy flood and waterlogging in rainy season.According to the land use statistics of Longtan, the current water surface rate of Longtan is $8.54 \%$ and the green land rate is 43.01\%.[ Fig.3] With the increase of hard surface ratio in development, it is inevitable to increase the surface rainfall runoff and change the hydrological characteristics of the original basement.For the ecological resilience development in the construction of Longtan new city, the core planning goal is to incorporate different ecological rain flood construction and management methods in different land use units.

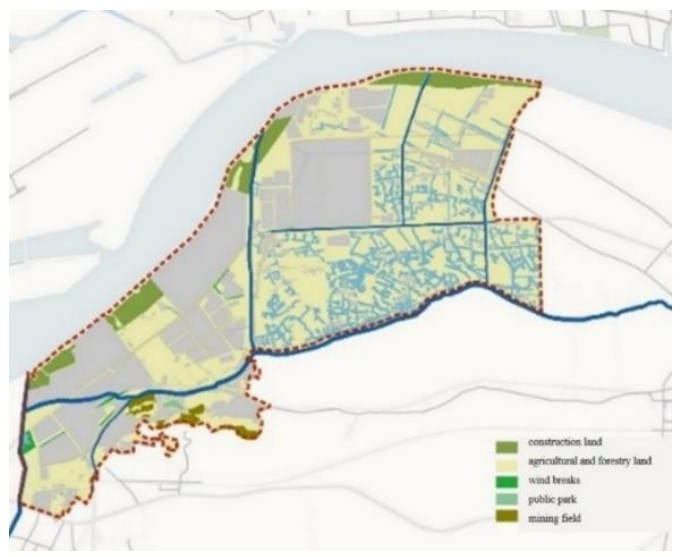

Fig. 3. Analysis of ecological land in Longtan new city

\subsubsection{Analysis of ecological sensitivity and construction suitability of Longtan new city}

The structure of ecological sensitivity analysis of Longtan new city was obtained by the superposition of biodiversity and river system factors through GIS spatial analysis.Among them, the high sensitive area accounts for $38 \%$, mainly in the constructed area.The medium sensitive area accounts for $49 \%$, mainly in the areas of agriculture and forestry. The high sensitive area accounts for $13 \%$, mainly in the areas of coastal tidal mudflats, river systems and mountains. [ Fig.4]

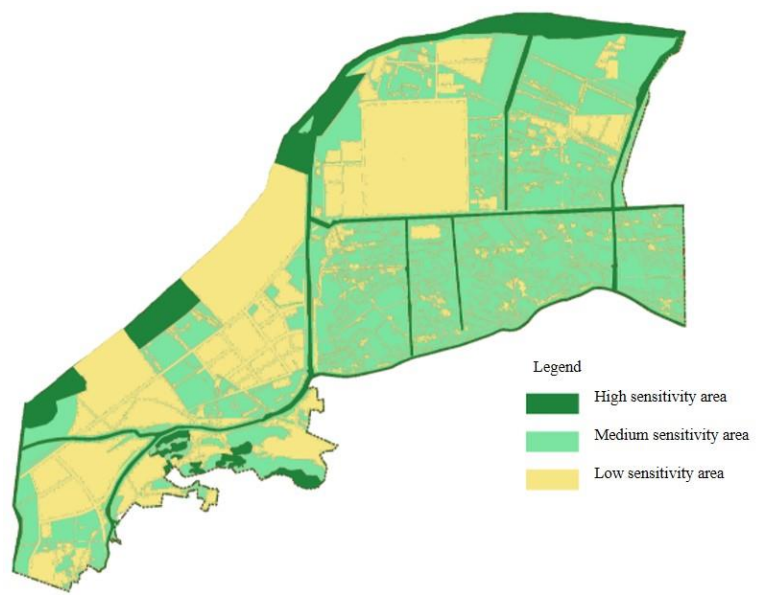

Fig. 4. Ecological sensitivity analysis

Through GIS spatial analysis, integrated slope, construction constraints and other factors, the construction suitability analysis results of the new city were obtained.Among them, the high suitability construction area accounts for $36 \%$, which is mainly the area with low ecological sensitivity and gentle slope.The medium suitability construction area accounts for $49 \%$, mainly for the ecologically sensitive area and the slope is less than $25 \%$. The low suitability construction area accounts for $15 \%$, mainly the area with high ecological sensitivity and the gradient is greater than $25 \%$. [Fig.5]The analysis of construction suitability is the basis of guidance for the suitable region of the construction of rain flood.

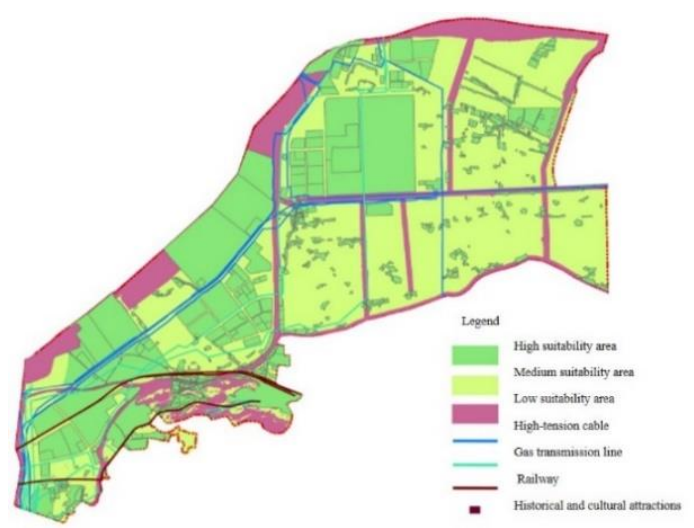

Fig. 5. Construction suitability analysis 


\subsection{Ecological priority of elastic rain flood construction planning}

\subsubsection{Elastic rain-flood control strategy in public green space system}

According to the analysis of the existing green space of Longtan new city and the sensitive points of regional drainage, the location of caverns suitable for construction is selected, including urban lake body, reservoir and public green space.The landscape of seasonal regulating and storage green space, and the landscape of different drought and flood effects are constructed.To ensure the residents' daily activities and the regulation and storage function of the rainstorm green area simultaneously.Before the runoff rainwater from the surrounding areas enters the low-impact development facilities in the urban green space and the square, the sedimentation tank and the preliminary pond should be used to pretreat the runoff rainwater that enters the green space.

Binjiang wetland is located in the southeast area of Longtan new city, and is currently used for coastal beaches, farmland, woodland, sewage treatment plant and part of industrial land.According to the overall planning of Longtan new city, the park will be developed into a wetland park and become the core of ecological conservation of the new city.Therefore, the research plan suggests that the ecological storm flood management mode should be integrated in this area, and the tail water of the sewage treatment plant should be purified by building a cascade wetland.The tail water of evolution flows into the river and eventually into the Yangtze river. [Fig.6]

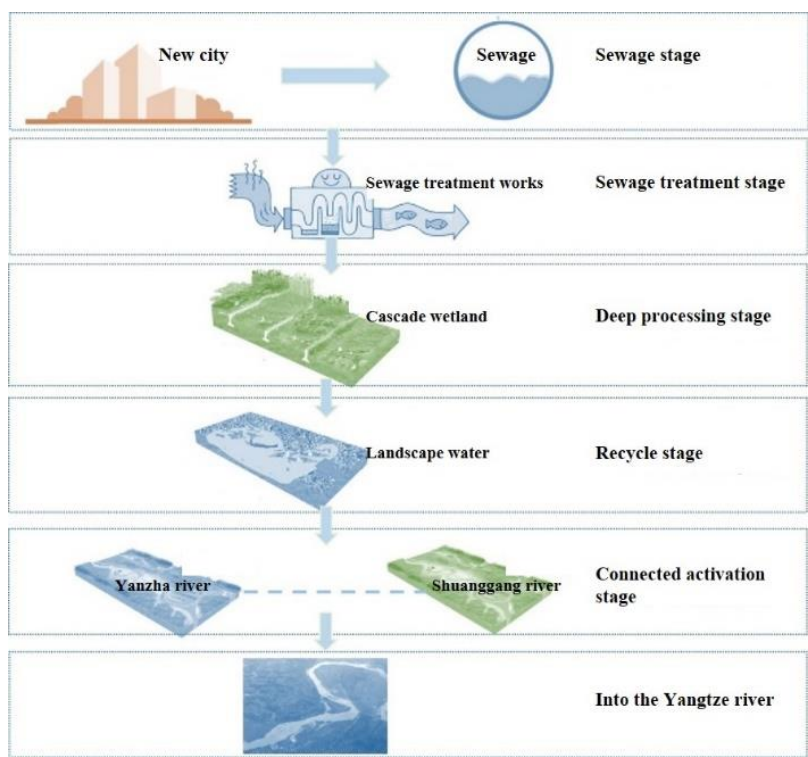

Fig. 6. Ecological cascade wetlands

On the basis of building the function of flood regulation and storage facilities in the riverside wetland, the function of ecological leisure should be brought into
play.The habitat conservation and leisure space construction are mainly used to compensate the affected organisms in the base.We will increase water-friendly, recreational and scientific and educational functions, integrate ecological protection and landscape beautification, and achieve harmonious coexistence between cities and nature. [ Fig.7]

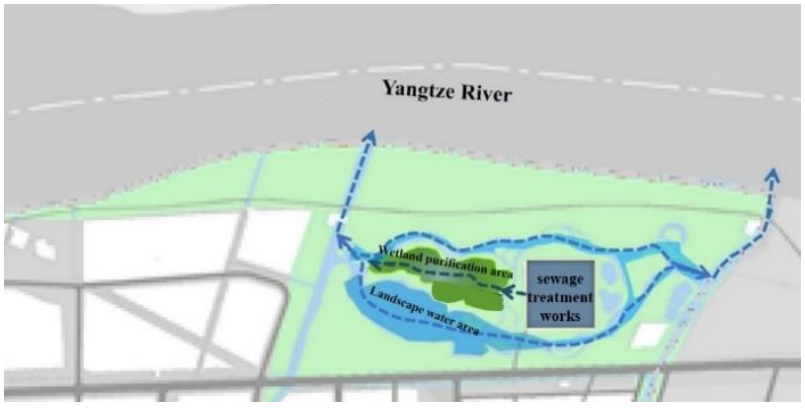

Fig. 7. Ecological rainflood function area of riverside wetland

The environmental ecological transformation of the sewage plant is also carried out. [ Fig.8]Combining the design of riverside wetland park, ecological reconstruction of existing sewage treatment plant.The function of science and education and recreation in the factory area can be improved by adding green land and closing the top of sedimentation tank to provide space for residents' activities. [ Fig.9]

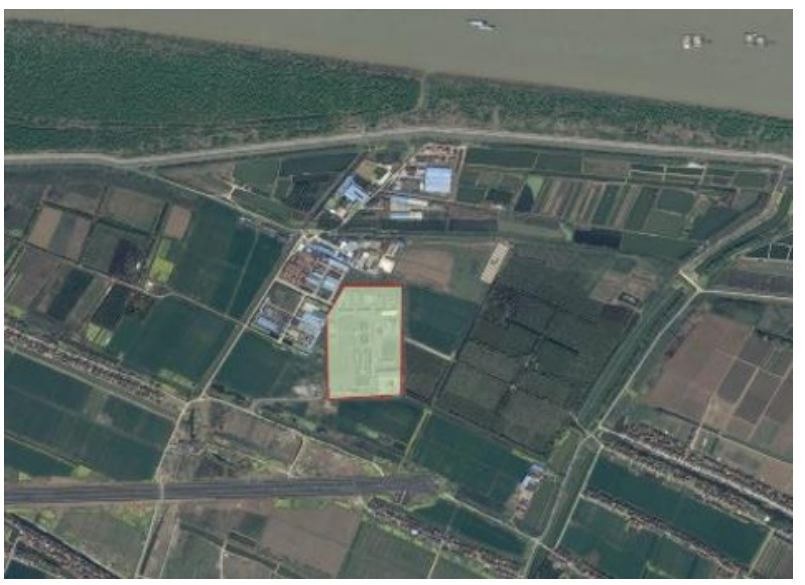

Fig. 8. Before transformation

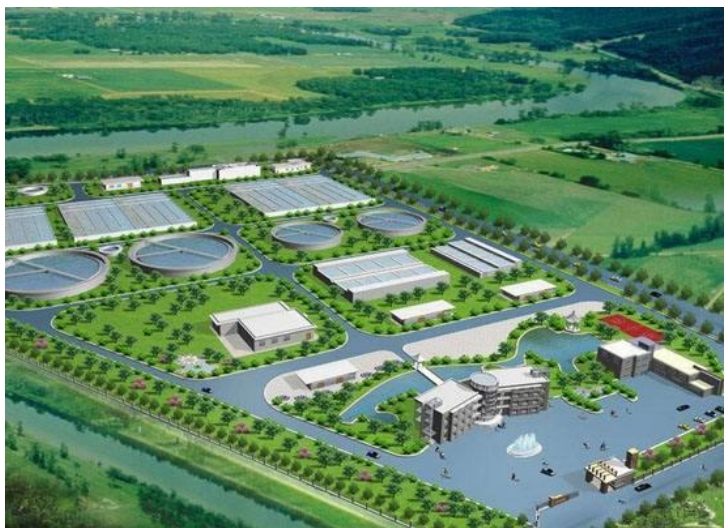

Fig. 9. After transformation 


\subsubsection{Elastic rain-flood control strategy in water system}

Protect the current status of rivers, lakes, wetlands, ponds, ditches and other natural urban water bodies.Make full use of the low-impact development facilities with the function of rainwater storage and purification. The layout, water level regulation and storage should be connected with the city's upstream rain water pipe system, excess storm runoff discharge system and downstream water system.Make full use of the present situation of Longtan new city natural water construction wet pond, rain wetland and other low-impact development facilities with the function of rainwater regulation and storage.The vertical elevation relationship between urban waterfront green land, water surface and surrounding land should be well handled, so that rainwater can enter into water body.Vegetation buffer zone and other facilities are set up to prevent pollution of urban water system.

\subsubsection{Elastic rain-flood control strategy in the road}

When the Longtan new city road passes or passes through the water source protection area, emergency treatment and storage facilities for rainwater should be designed on both sides of the road or downstream of the storm water pipe.Before the rainwater of road runoff enters the lowimpact development facilities in the red line inside and outside of the road, such as sedimentation tank and preflush pond should be used to pretreat the rainwater of runoff into the green space. Pavements and nonmotorized lanes should be constructed with permeable pavement, while the tensile and compressive strength of the permeable pavement in non-motorized lanes should also be considered. Ecological detention facilities are set up in the green belt of sidewalk, subdivision zone and green space outside the red line, so that the road runoff first enters each ecological detention facility, and the construction of rain water pipe network is carried out synchronously.

\subsubsection{Elastic rain-flood control strategies in residential areas and residential buildings}

Longtan new city residential area is a special area of rainwater utilization.Rain water from the roof of the community will enter the green space around the building through the drain pipe, and infiltrate the underground through the natural soil.The standard internal runoff can be fully infiltrated, and the excessive precipitation can be discharged into municipal sewage pipeline through the overflow system. When the rain water is greater than the soil infiltration capacity, the seepage trench or depression into the community. The residential buildings in Longtan new city, as the most convenient rainwater use unit, can use domestic rainwater more for flushing toilets or irrigating green Spaces.The roof rainwater will be collected and treated through the drain pipe, and the particulate pollutants will be removed through dispersing or several kinds of filtration.

\subsubsection{Elastic rain-flood control strategy in commercial land}

The large area commercial area of Longtan new city is the key object of urban rainwater utilization and the rainwater utilization system must be considered.Green roofs can be used in buildings with low roof gradient, and roof rainwater can be broken off and introduced into small, decentralized low-impact development facilities by means of rain falling-pipe connection or installation of gathering Wells.At the same time, to meet the needs of its specific population, including business negotiations, and create an open, multi-functional commercial low-impact development landscape.

\section{Benefit advantages of eco-priority flexible rainflood construction in new cities}

The construction and development of sponge city model is built through the elastic ecological rain flood management model.The new cities will greatly reduce flood risk and water load after construction.Strengthening the recharge of rainwater infiltration to groundwater will make up for the impact of urban development and improve the recovery and utilization of rainwater resources.[7]At the same time, the integration of green and ecological rain-flood facilities reduces the construction and investment of grey regulating and storage facilities, which is conducive to saving the cost of urban construction.It can also provide a green open space for the cities and supplement the ecological open space and hydrophilic space. [8]On the basis of overall consideration, land resources can be effectively utilized to improve the quality of regional human settlements and promote the land value of the new cities. [9]

\section{Conclusion}

New cities is the key area in the national urbanization process.It is of strategic significance to integrate and promote the ecological resilience of rain flood management and sponge development.However, there is still a certain gap between China and developed countries in terms of the management system and standards of ecorain flood in new city district. Based on the existing construction experience, we need to actively summarize and promote the development of laws and regulations in line with the construction mode of new cities and new districts in China.The concept of ecological rain flood management is implemented in the planning of new cities and new district and the development of ecological civilization.

In this paper, the management concept of rain flood construction and the method of sustainable construction in new urban areas of China are proposed.This paper puts forward some specific construction methods and guidelines for different types of land use patterns in new city construction. This method is of great reference significance for promoting the management of rain flood 
and sustainable development in the construction of new cities in China.However, how to apply this method systematically in new cities needs to be practiced and optimized in more new cities. This is also the focus of the next step of this study.

\section{Appendices}

Part of the data in this paper is from the land use statistics of the overall planning of Longtan new city.

\section{References}

1. Wu Che, Fangfang Lu, Junqi Li, et al.2009. Inspiration of typical storm flood management system in developed countries -- construction of modern storm flood control and utilization system in Chinese cities $[\mathrm{J}]$. China water supply and drainage, 25 (20) : 12-17

2. Jiang Cheng, Yongpeng Lu, Xiaofang Huang, et al.2009. Study on the environmental effect of the regulating pool of integrated drainage system in downtown Shanghai $[\mathrm{J}]$. Environmental science, 30 (8) : 2234-2240.
3. Haishun $\mathrm{Xu}$, Yongli Cai, Bing Zhao, Hao Wang, et al.2016. Theoretical method and practice of sponge city planning in urban new district $[\mathrm{M}]$. Beijing: China building industry press.

4. Linwei Zhang, Huiwei Xu, et al.2017. Typical case of sponge city construction [M]. Beijing: China building industry press.

5. Dexiang Li, et al.2011. Survey of European urban ecological construction [M]. Beijing: China building industry press.

6. Jingjing Dong.2012. Pilot study on rainwater utilization in lingang new city, Shanghai [D]. Shanghai: East China Normal University.

7. Junqi Li, Xinyu Zeng, Jiaming Lu.2008. Discussion on the quantitative method of urban rainwater collection standard $[\mathrm{J}]$. China water supply and drainage, 24 (10) : 1-6.

8. Center for Neighborhood Technology(CNT).2009.A Sustainable community-based Approach to Reducing non-point Source Pollution[R].Chicago, USA.

9. David r. Tilley, Mark t. Brown. 1998. The Wetland Networks for Storm water Management in Subtropical Urban Watersheds [J]. Ecological Engineering, (2) : 131-158. 